\title{
DEVELOPING THE BUSINESS MODELLING METHOD
}

\author{
L. O. Meertens, M. E. Iacob and L. J. M. Nieuwenhuis \\ University of Twente, PO Box 217, Enschede, The Netherlands \\ \{l.o.meertens, m.e.iacob, l.j.m.nieuwenhuis\}@utwente.nl
}

Keywords: Business modelling, Modelling method, Business models.

\begin{abstract}
Currently, business modelling is an art, instead of a science, as no scientific method for business modelling exists. This, and the lack of using business models altogether, causes many projects to end after the pilot stage, unable to fulfil their apparent promise. We propose a structured method to create "as-is" business models in a repeatable manner. The method consists of the following steps: identify the involved roles, recognize relations among roles, specify the main activities, and quantify using realistic estimates of the model. The resulting business model is suitable for analysis of the current situation. This is the basis for further predictions, for example business cases, scenarios, and alternative innovations. We offer two extra steps to develop these innovations and analyse alternatives. Using them may enable successful projects to be implemented, instead of ending on a shelf after the pilot stage.
\end{abstract}

\section{INTRODUCTION: BUSINESS MODELLING BACKGROUND}

A business model is critical for any company, and especially for any e-business. Its importance has been recognized over the past few years by several authors that have created different business model frameworks aimed at identifying the main ingredients of a business model (for example, Osterwalder (2004); for an overview, see Pateli \& Giaglis (2004), and Vermolen (2010)). However, the state in which this field finds itself is one of "prescientific chaos" (Kuhn 1970): there are several competing schools of thought, and progress is limited because of a lack of cumulative progress. Because of this, there are no clear and unique semantics in the research related to business models. The very concept of "business model" is associated with many different definitions (Vermolen 2010). The elements of such a business model differ significantly from one approach to another. Furthermore, to the best of our knowledge, there are no methodological approaches in the literature for the design and specification of business models (Vermolen 2010). This lack of cohesion in the field clearly diminishes the added value of business models for companies and makes business modelling an art, rather than a science. This state of affairs motivated us to propose such a method, which enables the development of business models in a structured and repeatable manner. Thus the contribution of this paper is three-fold:

- A business model development method;

- A definition of the concept of business model and the identification of its core elements, captured by the deliverables of the method steps;

- An illustration of the method by means of a case study from the healthcare domain.

The paper is structured as follows. Section 2 focuses on the discussion of the main concepts addressed in the paper, and positions our approach with respect to the existing design science and method engineering literature. In Section 3, we describe the steps of our business model development method. In Section 4, we demonstrate the method by means of a case study concerning the development of a qualitative business model of the elderly care in The Netherlands. Finally, we conclude our paper and give pointers to future work in Section 5.

\section{THEORETICAL BACKGROUND}

A simple analysis of the two words "business model" already gives an idea of what a business model is about. On the one hand, there is "business": the way a company does business or creates value. On the other hand, there is "model": a 
conceptualization of something - in this case, of how a company does business.

We extend this common and simplistic interpretation of a business model as "the way a company earns money", into a broader and more general definition of the concept: "a simplified representation that accounts for the known and inferred properties of the business or industry as a whole, which may be used to study its characteristics further, for example, to support calculations, predictions, and business transformation."

The last part of the definition above, namely the indication of the possible uses of a business model is of particular importance in the context of this paper. The method we propose not only facilitates the development of such a design artefact - a business model - but also takes a business engineering perspective. Thus, its application will result in two (or more) business models: one that reflects the "asis" situation of the business and one or more alternative "to-be" business models that represents possible modifications of the business as result of, for example, adoption of innovative technologies or more efficient business processes.

To the best of our knowledge, such a method does not exist yet for what we define as business models (Vermolen 2010). In the remainder of this section, we position our work in the contexts of design science and method engineering, to which it is related.

\subsection{Design Science}

A business modelling method can be seen as a design-science artefact. It is the process of creating a product: the business model. We use the seven guidelines of Hevner et al. (2004) to frame how we use the methodology engineering approach from Kumar \& Welke (1992) to create our method.

The first guideline advises to design as an artefact. Design-science research must produce a viable artefact in the form of a construct, a model, a method, or an instantiation. As said, we produce a method.

The second guideline tackles relevance. The objective of design-science research is to develop technology-based solutions to important and relevant business problems. Viable business models lie at the heart of business problems. However, our solution is not yet technology-based. Partial automation of the method is left for future research.

The utility, quality, and efficacy of a design artefact must be rigorously demonstrated via wellexecuted evaluation methods. We demonstrate the business modelling method using a case study. We leave more rigorous evaluation for further research.

Research contribution is the topic of the fourth guideline. Effective design-science research must provide clear and verifiable contributions in the areas of the design artefact, design foundations, and/or design methodologies. We provide a new artefact to use and study for the academic world. The methodology may be extended, improved, and specialized.

Guideline five expresses the scientific rigour: Design-science research relies upon the application of rigorous methods in both the construction and evaluation of the design artefact. We aim to be rigorous through using the methodology engineering approach. Existing, proven methods are used as foundation and methods where applicable. Evaluation was handled in the third guideline.

The sixth guideline positions design as a search process. The search for an effective artefact requires utilizing available means to reach desired ends while satisfying laws in the problem environment. Whenever possible, we use available methods for each of the steps. Following the methodology engineering approach helps us to satisfy the laws for creating a new methodology.

The final guideline instructs us to communicate our research. Design-science research must be presented effectively both to technology-oriented as well as management-oriented audiences. This article is one of the outlets where we present our research.

\subsection{Methodology Engineering}

Methodologies serve as a guarantor to achieve a specific outcome. In our case, this outcome is a consistent and better-informed business model. We aim to understand (and improve) how business models are created. With this understanding, one can explain the way business models help solve problems. We provide a baseline methodology only, with a limited amount of concepts. Later, we can extend, improve and tailor the methodology to specific situations or specific business model frameworks.

The business modelling method has both aspects from the methodology engineering viewpoint: representational and procedural (Kumar \& Welke 1992). The representational aspect explains what artefacts a business modeller looks at. The artefacts are the input and deliverables of steps in the method. The procedural aspect shows how these are created and used. This includes the activities in each step, tools or techniques, and the sequence of steps. 


\section{DEFINING THE BUSINESS MODELLING METHOD}

We define five individual step of business modelling, which the rest of this section elaborates. To describe each step, we use the following elements:

- inputs of the step,

- activities to perform during the step,

- possible techniques to use during the step's activities, and

- deliverables resulting from the step.

Each step in the proposed method requires specific methods, techniques or tools that are suitable for realizing the deliverables. We will mention examples of those. However, others may also be useful and applicable, and it is not our aim to be exhaustive in this respect. Table 1 shows an overview of our method.

\subsection{Create As-Is Model}

As mentioned in the previous section, our business model development method takes business engineering perspective. Thus, the first four steps of our method focus on creating a business model that reflects the current state of the business. Therefore, steps one through four create an as-is model.

\subsubsection{Step 1: Identify Roles}

Identifying the relevant parties (which we refer to as roles) involved in a business model should be done as systematically as possible. The aim is completeness in this case. The business modeller must carry out a stakeholder analysis, to identify all roles. The input to this step includes for example, documentation, domain literature, interviews, experience and previous research. The output is a list of roles.

For an example of stakeholder analysis method, we refer to Pouloudi \& Whitley (1997). They provide an interpretive research method for stakeholder analysis aimed at inter-organizational systems, such as most systems where business modelling is useful. The method consists of the following steps:

1. Identify obvious groups of stakeholders.

2. Contact representatives from these groups.

3. (In-depth) interview them.

4. Revise stakeholder map.

5. Repeat steps two to four, until...
Pouloudi and Whitley do not list the fifth step, but mention that stakeholder analysis is a cumulative and iterative approach. This may cause the number of stakeholders to grow exponentially, and the question remains when to stop. Lack of resources may be the reason to stop the iterative process at some point. Closure would be good, but seems hard to achieve when the model is more complex. Probably, the modeller has to make an arbitrary decision. Nevertheless, one should choose stop criteria (a quantifiable measure of the stakeholder's relevance for the respective business model and a threshold for the measure) before starting the process (Pouloudi 1998).

"Revising the stakeholder map" (step four) could use extra explanation, which can be found in the description of the case Pouloudi and Whitley use to explain the method. The stakeholders gathered from interviews can be complemented with information found in the literature. The business modeller then refines the list of stakeholders by focussing, aggregating, and categorizing.

\subsubsection{Step 2: Recognize Relations}

The second step of our method aims to discover the relations among roles. The nature of these relations may vary substantially, but it always involves some interaction between the two roles and may assume some exchange of value of some kind. Much of the work and results from the previous step can be reused for this as input. In theory, all roles could have relations with all other roles. However, in practice, most roles only have relations with a limited number of other roles. Usually, these relations are captured in a stakeholder map, which often follows a hub-and-spoke pattern, as the focus is on one of the roles. This pattern may be inherent to the approach used, for example if the scope is defined as a maximum distance from the focal role.

To specify all relations, we suggest the use of a role-relation matrix with all roles on both axes as technique. Of this matrix, the cells point out all possible relations among the roles. Each of the cells could hold one or more relations between two roles. Assuming that roles have a limited number of relations, the role-relation matrix will be partially empty. However, one can question for each empty cell whether a relation is missing or not.

Cells above and below the diagonal can represent the directional character of relations. Usually, relations have a providing and consuming part. The providing part goes in the upper half of the matrix, and the consuming part in the bottom half. This 
Table 1: Business Modelling Method.

\begin{tabular}{|l|l|l|l|}
\hline Step & Inputs & Techniques or Tools & Deliverables \\
\hline $\begin{array}{l}\text { Identify } \\
\text { Roles }\end{array}$ & $\begin{array}{l}\text { Documentation, domain literature, } \\
\text { interviews, experience, previous } \\
\text { research }\end{array}$ & $\begin{array}{l}\text { Stakeholder analysis (Pouloudi \& Whitley } \\
\text { 1997) }\end{array}$ & Role list \\
\hline $\begin{array}{l}\text { Recognize } \\
\text { Relations }\end{array}$ & $\begin{array}{l}\text { Role list, Stakeholder map, value } \\
\text { exchanges }\end{array}$ & e3-value (Gordijn 2002) & Role-relation matrix \\
\hline $\begin{array}{l}\text { Specify } \\
\text { Activities }\end{array}$ & $\begin{array}{l}\text { Role-relation matrix, Role list, } \\
\text { business process specifications }\end{array}$ & BPM methods, languages and tools & List of activities \\
\hline $\begin{array}{l}\text { Quantify } \\
\text { Model }\end{array}$ & $\begin{array}{l}\text { Process specifications, accounting } \\
\text { systems and annual reports }\end{array}$ & Activity based costing & $\begin{array}{l}\text { Total cost of the business } \\
\text { "as-is" }\end{array}$ \\
\hline $\begin{array}{l}\text { Design } \\
\text { Alternatives }\end{array}$ & $\begin{array}{l}\text { As-is business model, Ideas for } \\
\text { innovations and changes }\end{array}$ & $\begin{array}{l}\text { Business modelling method (steps 1 to 4), } \\
\text { Brainstorming }\end{array}$ & $\begin{array}{l}\text { One or more alternative } \\
\text { business models }\end{array}$ \\
\hline $\begin{array}{l}\text { Analyse } \\
\text { Alternatives }\end{array}$ & Alternative business models & $\begin{array}{l}\text { Sensitivity analysis, technology assessment, } \\
\text { interpolation, best/worst case scenarios }\end{array}$ & $\begin{array}{l}\text { Business case for each } \\
\text { alternative }\end{array}$ \\
\hline
\end{tabular}

especially helps with constructions that are more complex, such as loops including more than two roles.

The output of this step is a set of relations.

\subsubsection{Step 3: Specify Activities}

For a first qualitative specification of the business model, the next step is to determine the main activities. Relations alone are not sufficient: the qualitative model consists of these main business activities (business processes) too. These activities originate from the relations identified in the previous step. Each of the relations in the role-relation matrix consists of at least one interaction between two roles, requiring activities by both roles. Besides work and results from the previous steps, existing process descriptions can be valuable input. Techniques from business process management may be used.

The output from these first three steps is a first qualitative business model, including roles, relations and activities. It reveals what must happen for the business to function properly.

\subsubsection{Step 4: Quantify Model}

Quantifying the business model helps us to see what is happening in more detail and compare innovations to the current situation. To turn the qualitative model into a quantitative model, numbers are needed. The numbers are cost and volume of activities (how often they occur). Together, these numbers form a complete view of the costs captured by the business model.

Several sources for costs and volumes are possible, such as accessing accounting systems or (annual) reports. The resulting quantitative business model shows the as-is situation.

\subsection{Develop To-Be Model}

The as-is model, created in previous steps, is suitable for analysis of the current state only. However, from the as-is model, it is possible to derive alternatives. Such alternatives can be created to assess how reorganisations, innovations or other changes influence the business. These are the to-be models.

\subsubsection{Step 5: Design Alternatives}

From here on, we aim to capture a future state of the business in a business model. To make predictions, the model may need further instantiations. Each instantiation is an alternative development that may happen (to-be). Using techniques such as brainstorming and generating scenarios, business modellers create alternative, qualitative, future business models. These alternatives are used to make predictions. Usually, such alternatives are built around a (technical) innovation. This may include allocating specific roles to various stakeholders. A base alternative, which only continues an existing trend without interventions, may help comparing the innovations. Next to the business model, ideas for innovations serve as input. The resulting alternative business models show future (to-be) possibilities.

\subsubsection{Step 6: Analyse Alternatives}

The final step for a business modeller is to analyse the alternative business models. Besides the qualitative business models, several sources of input 
are possible to quantify the alternatives. Applicable techniques include sensitivity analysis, technology assessment, interpolation and using best/worst case scenarios. Each alternative can be tested against several scenarios, in which factors change that are not controllable. We can use the models to predict the impact. This step and the previous one can be repeated several times to achieve the best results. The final output is a business case (including expected loss or profit) for each alternative.

\section{THE U*CARE CASE: DEMONSTRATING THE BUSINESS MODELLING METHOD}

$\mathrm{U}^{*}$ Care is a project aimed at developing an integrated (software) service platform for elderly care ( $\mathrm{U}^{*}$ Care Project n.d.). Due to the aging population and subsequently increasing costs, elderly care - and healthcare in general - is one of the areas where governments fund research. However, many projects never get further than pilot testing. Even if the pilot is successful, the report often ends on a shelf. By applying the business modelling method, we plan to avoid this and put the $\mathrm{U}^{*}$ Care platform into practice. Specifically, we aim to show how the technological innovations built in the $U^{*}$ Care platform will influence the business model for elderly care.

The $\mathrm{U}^{*}$ Care case is in progress currently, and therefore, it is suitable for demonstrating the first three steps of the business modelling method. These three steps result in a qualitative business model of the as-is situation of the elderly care. At this time, we are collecting quantitative data. Therefore, steps four to six of the method are not yet possible and we will not address them here. However, they will be subject of future work.

\subsection{Identify Roles}

The first step of the stakeholder analysis, led to the identification of several groups of obvious stakeholders. The groups include all the project partners, as their participation in the project indicates their stake. Another group includes the main users of the platform: the clients and employees of the elderly care centre.

After identifying the obvious stakeholders, we contacted and interviewed representatives from all the project partners and several people in the care centre. These interviews did not explicitly focus on stakeholder analysis, but served as a general step in requirements engineering. Table 2 displays a partial list of identified stakeholders after steps two and three of Pouloudi and Whitley's method for stakeholder analysis have been performed.

Table 2: Partial list of stakeholders after step three of Pouloudi and Whitley's method for stakeholder analysis.

\begin{tabular}{|l|l|}
\hline Clients & Care (\& wellness) providers \\
\hline Volunteer aid & Hospitals \\
\hline Nurses & Elderly care centres \\
\hline Doctors & Psychiatric healthcare \\
\hline Administrative employees & Homecare \\
\hline General practitioners & Technology providers \\
\hline Federal government & User organizations \\
\hline Local government & Insurance companies \\
\hline
\end{tabular}

The fourth step includes a search for stakeholders in the literature. Besides identifying the extra stakeholders, the literature mentioned the important issue that some actors in the list are individual players, while other actors are organizations or other forms of aggregations (groups). Consequently, overlap can occur in the list of actors.

The final action of the first iteration is not a trivial one. Refining the stakeholder list requires interpretation from the researcher. Different stakeholder theories (for example, E. J. Emanuel \& L. L. Emanuel (1996), J. Robertson \& S. Robertson (2000), and Wolper (2004)) act as tools to minimize subjectivity.

The long list of identified stakeholders is not practical to continue with and has much overlap. Therefore, we grouped the stakeholders into a limited set of roles, shown in Table 3. This set of high-level roles is an interpretive choice. The small set helps to keep the rest of case clear instead of overcrowded. The larger set is kept in mind for the to-be situation to find potential "snail darters": stakeholders with only a small chance of upsetting a plan for the worse, but with huge results if they do (Mason \& Mitroff 1981). The small set of stakeholders was subject to prioritization based on Mitchell et al. (1997). While the prioritization is subjective, it shows that all roles in the list are important.

\subsection{Recognize Relations}

The current situation consists of five categories of interacting roles. Table 3 shows them on both axes. The cells show relations between the roles. While 
Table 3: Role-relation matrix.

\begin{tabular}{|c|c|c|c|c|c|}
\hline $\begin{array}{l}\text { Consumer } \\
\text { Provider }\end{array}$ & Care consumers & Care providers & $\begin{array}{l}\text { Technology } \\
\text { providers }\end{array}$ & Government & Insurers \\
\hline Care consumers & $\mathrm{X}$ & Pay for care & & $\begin{array}{l}\text { Pay for AWBZ } \\
\text { Pay for WMO }\end{array}$ & $\begin{array}{l}\text { Pay for } \\
\text { insurance }\end{array}$ \\
\hline Care providers & $\begin{array}{l}\text { Provide } \mathrm{ZVW} \text { care } \\
\text { Provide WMO care } \\
\text { Provide AWBZ care }\end{array}$ & $\mathrm{X}$ & $\begin{array}{l}\text { Pay for (use of) } \\
\text { technology or } \\
\text { service }\end{array}$ & $\begin{array}{l}\text { Provide care to } \\
\text { citizens }\end{array}$ & $\begin{array}{l}\text { Provide care } \\
\text { to insured }\end{array}$ \\
\hline $\begin{array}{l}\text { Technology } \\
\text { providers }\end{array}$ & & $\begin{array}{l}\text { Provide technology } \\
\text { or service }\end{array}$ & $\mathrm{X}$ & & \\
\hline Government & $\begin{array}{l}\text { Provide AWBZ } \\
\text { insurance } \\
\text { Provide WMO } \\
\text { insurance }\end{array}$ & $\begin{array}{l}\text { Pay for WMO care } \\
\text { to citizens }\end{array}$ & & $\mathrm{X}$ & $\begin{array}{l}\text { Pay for } \\
\text { AWBZ care to } \\
\text { citizens }\end{array}$ \\
\hline Insurers & $\begin{array}{l}\text { Provide insurance } \\
\text { Refund AWBZ and } \\
\text { ZVW care }\end{array}$ & & & $\begin{array}{l}\text { Ensure AWBZ care } \\
\text { for citizens }\end{array}$ & $\mathrm{X}$ \\
\hline
\end{tabular}

the care provider has relations with all the other roles, it is not a clear hub-and-spoke pattern. Several of the other roles have relations outside the care provider.

The relations show that a main goal of the business is to provide care to the care consumer. The insurers and government handle much of the payment. Other (regulating) roles of the government remain out of scope, as the case is complex enough as it is.

The insurers handle most of the payments. The patient has to pay the care provider after receiving care. The patient can then declare the costs to the insurance company, which refunds the patient. The patient pays a premium to the insurance company. According to the Dutch Healthcare Insurance Act (Zorgverzekeringswet, ZVW), every citizen has to have basic care insurance (ZVW). For "uninsurable care" (including most home healthcare, similar to USA Medicare), the Dutch government set up a social insurance fund, termed General Exceptional Medical Expenses Act (Algemene Wet Bijzondere Ziektekosten, AWBZ). All employees and their employers contribute towards this fund. The AWBZ is similar to the regular insurance companies, except for collecting the premium. The premium is paid through taxation by the government, which outsources most of the further actions to insurers. A similar system is set up for wellness homecare, such as cleaning. This is the Social Support Act (Wet Maatschappelijke Ondersteuning, WMO). In contrast to the AWBZ, the government takes care of all actions itself, through its municipalities.

Several issues exist, which we do not handle in detail here. For example, it is inherent to insurance that not all people who pay premium are also (currently) care consumers.

\subsection{Determine Behaviour}

Most of the relations between the roles in Table 3 start with verbs. This signals that they are (part of) behaviour. Any relation not beginning with a verb is a candidate for rephrasing or being split into smaller parts.

Besides the relations, we focussed on AWBZ to identify the main activities of the care providers. "Providing care" has four top-level functions: personal care, nursing, guidance/assistance, and accommodation. Each of these functions consists of many detailed activities, of which Table 4 provides an example.

We obtained these activities from documents made available by the government for reimbursement purposes (Ministry of Health, Welfare and Sport 2008). As it also provides an indication of volume (times a day) and a first indication of costs (minutes spent), it is a first step towards quantifying the model.

\subsection{Further Steps}

The other three steps are not possible for now, as detailed quantitative data is not available yet. However, when we have developed a quantitative business model, the final steps of the method help to generate business cases easily for various services that could be integrated into the $\mathrm{U}^{*}$ Care platform. This should proof their viability and lead to implementation, instead of ending on the shelf. 
Table 4: Example of personal care activities.

\begin{tabular}{|l|l|l|l|}
\hline Activity & Actions & $\begin{array}{l}\text { Time in } \\
\text { minutes }\end{array}$ & $\begin{array}{l}\text { Frequency } \\
\text { per day }\end{array}$ \\
\hline Washing & Whole body & 10 & $1 \mathrm{x}$ \\
& Parts of body & 20 & $1 \mathrm{x}$ \\
\hline Dressing & Un)dress completely & 15 & $2 \mathrm{x}$ \\
& Undress partially & 10 & $1 \mathrm{x}$ \\
& Dress partially & 10 & $1 \mathrm{x}$ \\
& Put on compression stockings & 10 & $1 \mathrm{x}$ \\
& Take off compression stockings & 7 & $1 \mathrm{x}$ \\
\hline Getting in and out of bed & Help getting out of bed & 10 & $1 \mathrm{x}$ \\
& Help getting into bed & 10 & $1 \mathrm{x}$ \\
& Help with afternoon rest (for example, get onto the couch) & 10 & $1 \mathrm{x}$ \\
& Help with afternoon rest (for example, get off the couch) & 10 & $1 \mathrm{x}$ \\
& & & 10 \\
\hline Eating and drinking & Help with eating cold meals (excluding drinking) & $2 \mathrm{x}$ \\
& Help with eating warm meal (excluding drinking) & 15 & $1 \mathrm{x}$ \\
& Help with drinking & 10 & $6 \mathrm{x}$ \\
\hline
\end{tabular}

\section{CONCLUSIONS: A FUTURE FOR BUSINESS MODELLING}

Three contributions are made in this paper. Primarily, we created a business model development method. Secondly, we defined the concept of business model and identified its core elements, captured by the deliverables of the method steps. Finally, we demonstrated the method by means of a case study from the healthcare domain.

The business modelling method provides a way to create business models. Innovators can apply the steps to create business cases for their ideas systematically. This helps them to show the viability and get things implemented.

We provide a new design-science artefact to use and study for the academic world. As business modelling has several goals, conducting only the first few steps may be enough. For example, if your goal is to achieve insight in the current state only, the last two steps are not useful.

The business modelling method may be extended. Situational method engineering seems suitable for this (Henderson-Sellers \& Ralyté 2010). For example, for information system development, it is interesting to research if steps towards enterprise architecture can be made from business models. This can be seen as a higher-level form of, or preceding step to, the BMM proposed by Montilva and Barrios (2004). On the other side, a step could be added before identifying roles. Other domains require different improvements.
In addition, the steps in the method can be further specified. The steps can be detailed further. One of the ways to do this is to tailor the techniques at each of the steps of this method. In the future, new tools and techniques may help provide partial automation.

\section{ACKNOWLEDGEMENTS}

This work is part of the IOP GenCom U-CARE project, which the Dutch Ministry of Economic Affairs sponsors under contract IGC0816.

\section{REFERENCES}

Emanuel, E. J. \& Emanuel, L. L., 1996. What is Accountability in Health Care? Annals of Internal Medicine, 124, pp.229-239.

Gordijn, J., 2002. Value-based Requirements Engineering: Exploring Innovative e-Commerce Ideas. PhD Thesis. Vrije Universiteit Amsterdam.

Henderson-Sellers, B. \& Ralyté, J., 2010. Situational Method Engineering: State-of-the-Art Review. Journal of Universal Computer Science, 16(3), pp.424-478.

Hevner, A. R. et al., 2004. Design Science in Information Systems Research. MIS Quarterly, 28(1), pp.75-105.

Kuhn, T. S., 1970. The Structure of Scientific Revolutions, University of Chicago Press.

Kumar, K. \& Welke, R. J., 1992. Methodology Engineering: a proposal for situation-specific methodology construction. In Challenges and 
Strategies for Research in Systems Development. John Wiley series in information systems. Chichester: Wiley, p. 257-269.

Mason, R. O. \& Mitroff, I. I., 1981. Challenging strategic planning assumptions : theory, cases, and techniques, Wiley.

Ministry of Health, Welfare and Sport, 2008. Beleidsregels indicatiestelling AWBZ 2009.

Mitchell, R. K., Agle, B. R. \& Wood, D. J., 1997. Toward a theory of stakeholder identification and salience: Defining the principle of who and what really counts. Academy of management review, pp.853-886.

Montilva, J. C. \& Barrios, J. A., 2004. BMM: A Business Modeling Method for Information Systems Development. CLEI Electronic Journal, 7(2).

Osterwalder, A., 2004. The Business Model Ontology - a proposition in a design science approach. $\mathrm{PhD}$ Thesis. Universite de Lausanne.

Pateli, A. G. \& Giaglis, G. M., 2004. A research framework for analysing eBusiness models. European Journal of Information Systems, 13(4), pp.302-314.

Pouloudi, A., 1998. Stakeholder Analysis for Interorganisational Information Systems in Healthcare. PhD Thesis. London School of Economics and Political Science.

Pouloudi, A. \& Whitley, E. A., 1997. Stakeholder identification in inter-organizational systems: gaining insights for drug use management systems. European Journal of Information Systems, 6, p.1-14.

Robertson, J. \& Robertson, S., 2000. Volere: Requirements specification template, Technical Report Edition 6.1, Atlantic Systems Guild.

$\mathrm{U}^{*}$ Care Project, $\mathrm{U}^{*}$ Care website. Available at: http://www.utwente.nl/ewi/ucare/ [Accessed May 2, 2011].

Vermolen, R., 2010. Reflecting on IS Business Model Research: Current Gaps and Future Directions. In Proceedings of the 13th Twente Student Conference on IT. Twente Student Conference on IT. Enschede, Netherlands: University of Twente.

Wolper, L. F., 2004. Health care administration: planning, implementing, and managing organized delivery systems, Jones \& Bartlett Publishers. 